\title{
Elaboração de perdas por mulheres maduras saudáveis
}

\author{
Sandra Augusta de Melo \\ Anália S. Costa \\ Graciela Cardarelli \\ Livia Santa Cecília Moraes \\ Centro Universitário do Triângulo
}

\begin{abstract}
RESUMO
Este estudo pretendeu mergulhar no campo psicológico de mulheres maduras saudáveis, levantando dados sobre a maneira como lidaram com as perdas que lhe foram imputadas pela vida, sejam elas reais ou imaginárias. A pesquisa investigou a forma como essas mulheres elaboraram seus lutos. Constituiu-se numa pesquisa exploratória, com método qualitativo e clínico com abordagem psicodinâmica. Os dados foram coletados em entrevistas que foram gravadas, transcritas e interpretadas. Como resultado, obteve-se que, diante das perdas, houve o fortalecimento do Ego nas três mulheres investigadas; sendo assim, a experiência foi elaborada de forma positiva, bem sucedida, funcionando como uma alavanca para o crescimento. Isso se traduz em mais força e segurança pessoal, ou seja, em auto-estima. As mulheres demonstraram ter consciência de suas limitações, tanto quanto de sua força, ou seja, de sua capacidade de superar obstáculos. Conclui-se que a passagem normal pelo luto trouxe-lhes a possibilidade de re-significação das perdas, o apaziguamento de aspectos negativos inerentes à ambigüidade que elas imputam, e possibilitou a formação de novos vínculos, provavelmente em função de uma maior integração da personalidade em seus aspectos negativos e positivos.
\end{abstract}

Palavras-chave: mulheres; luto; elaboração de perdas.

\begin{abstract}
Elaboration on losses experienced by healthy mature women

The intention of this study was to delve into the psychological aspects of selected healthy and mature women, with respect to the manner in which they dealt with personal losses that had been experienced in life - either real or imaginary. The research investigated the way in which these women expressed their mourning. It is a exploratory research, using qualitative and clinical methods. Data had been collected through interviews which were recorded, and subseqently transcribed and interpreted. A particular observation was that prior to their loss, three of the women had a strong sense of self, and thus their experience was elaborated positivelly, successfullly, and seen as an element for for the growth. This resulted in more self-force and sense of personal security. These women demonstrated an awareness of their limitations as much as their strengh, and this enabled their ability to surpass obstacles. It is concluded that normal development of mourning brought the possibility of understanding their loss, the overcoming of negative aspects inherent to the ambiguity that these losses impute, and made possible the formation of new bonds; most likely as a function of a better integration of the personality in its negative and positive aspects.
\end{abstract}

Keywords: women; mourning; loss elaboration.

Não obstante a definição de saúde mais aceita nos meios científico e acadêmico seja aquela originária do preâmbulo da Constituição da Organização Mundial de Saúde - OMS, que enfatiza o bem estar para além da ausência de patologia, pode-se afirmar que os aspectos favoráveis à saúde da mulher, assim como do humano em geral, têm sido estudados pela psicologia e, portanto, predominantemente conhecidos, a partir de estudos das doenças, seu desenvolvimento, sintomas e causas.

Este trabalho pretendeu contribuir, através de uma pesquisa qualitativa, com o mapeamento de uma forma saudável de lidar com a vida, iniciando a construção de um esboço - que, espera-se, terá sequiência em novas pesquisas - daquilo que efetivamente se deve buscar na clínica, especialmente a preventiva: a saúde e a qualidade de vida, mais do que a subtração de patologias ou formas pouco saudáveis de lidar com a realidade dos fatos da vida.

Para falar de maturidade saudável, D' Andréa (1997, p. 130) afirma que:

Na meia idade o individuo começa a receber os dividendos de seus investimentos vitais. $O$ resultado global para quem aplicou bem as suas potencialidades e recebeu estímulo para seu desenvolvimento, é a maturidade propriamente dita. Entendemos essa maturidade como clímax da história pessoal, o ponto em que o indivíduo conseguiu plasmar um conjunto de traços que o 
definem, frente a si mesmo e aos demais, como uma pessoa realizada.

A avaliação da vida que se levou e que se construiu, quando se chega à maturidade parece ser, portanto, um fator de bem-estar. Entretanto, com os avanços na área médica e o aumento da longevidade, a maturidade passa a ser vista como uma época em que não está em jogo somente "colher frutos", mas um tempo de busca de sentidos.

A saúde da psique deve ser avaliada em termos de crescimento emocional, consistindo numa questão de maturidade. $O$ ser humano saudável é emocionalmente maduro tendo em vista sua idade no momento. A maturidade envolve gradualmente o ser humano numa relação de responsabilidade para com o ambiente. (Winnicott, 1990, p. 30)

A saúde que aqui é entendida, em seus aspectos físico e psíquico, considera a ausência de patologias do corpo ou de quadros de transtornos mentais e comportamentais, somados à sensação de bem-estar e boa adaptação social. Estes aspectos estão entrelaçados, inter-relacionados e decorrem uns dos outros, tornando o conceito de saúde algo a ser compreendido em sua pluri e inter causalidade. O bem-estar envolve tanto aspectos da individualidade como da vida em grupo:

$O$ bom relacionamento se instaura somente entre indivíduos que são capazes de cuidar de si mesmos. Aqueles que alcançaram esse grau de maturidade pessoal podem tornar-se muito unidos e livres para viver. Isso é possível porque são capazes de atuar também individualmente, tendo cada um a própria carreira, a própria vida e os próprios amigos. (Giusti, 1987, p. 94)

Do ponto de vista intrapsíquico, vale lembrar que "uma pessoa madura é a resultante de um perfeito desenvolvimento do Ego, implicando numa adequada adaptação ao princípio da realidade e num harmônico entrosamento com o Superego" (D'Andréa, 1997, p. 131).

Isso significa dizer que a pessoa madura - conceito que, em muitos momentos e autores, é associado ao de pessoa saudável - é aquela que consegue lidar com as demandas da realidade compartilhada de maneira ponderada, privilegiando o pensamento mais do que respostas automáticas. $\mathrm{O}$ superego, representante da moral, dos valores e normas, passa, com a saúde, a funcionar sob a égide do Ego, como uma opinião a ser ponderada e avaliada pelo pensamento, e não como uma lei implacável. Na maturidade, a moral imatura do Superego é substituída pela ética madura do Ego (D’Andrea, 1997).

O princípio de realidade caracteriza o processo secundário através do qual se lida com a realidade externa na busca do prazer e evitação da dor. É uma característica desse modo de funcionamento o pensamento, que é o ensaio de ação que busca administrar a frustração (Freud, 1911/1980).
As frustrações foram o alvo desse estudo. Elas são pinçadas das experiências de vida descritas pelos sujeitos sob a forma prototípica de perdas concretas. Isso é, esse estudo, procurou compreender a forma como os sujeitos investigados lidam com as situações de perda em suas vidas, e busca estabelecer nexos entre a maneira como as mulheres maduras saudáveis investigadas lidam com suas perdas - qualidade do princípio de realidade - e o fato de terem alcançado uma idade madura com saúde.

À medida que se amadurece, somam-se experiências de perdas na vida. Isso não é prerrogativa da maturidade ou da velhice (conceitos que estão sendo relativizados pelo aumento da perspectiva de vida), tendo em vista que a vida começa com a perda do útero.

Lino-Silva (1990) oferece uma perspectiva que relaciona perdas à aprendizagem, que se inicia com aquilo que é, ao mesmo tempo, a perda e o desenclausuramento do útero:

... nascer/dar-à-luz é uma ruptura, um partir-se no duplo sentido da palavra, que mais se acentua e se repete ao longo da vida: de repente o homem se percebe num mundo estranho e percebe a si mesmo como estranho. E cada crescimento, cada aprendizagem é uma separação, uma renúncia. (Lino-Silva, 1990, p. 56)

Assim, a forma como se administra os lutos, ou seja, a ação do princípio de realidade sobre as perdas, parece ser uma construção que é feita durante toda a existência e que é re-significada e construída a cada separação, cada perda, cada frustração. Perder e ganhar não são excludentes, mas diferentes faces da experiência humana.

Quando chega à maturidade, a pessoa já teve a oportunidade de viver algumas importantes perdas e supõe-se que isso, ou seja, o aprendizado em lidar com a frustração da perda e em reconhecer os ganhos, tenha sido incorporado à sua personalidade de maneira a auxiliá-la a lidar com a realidade.

Cataldo Neto e Majola (1997, p. 9) definem luto como: "um processo de elaboração e resolução de uma perda real ou fantasiosa pelo qual todos passam em algum momento da vida, com maior ou menor sucesso". E os autores prosseguem falando das consequiências que um luto bem sucedido traz para a vida das pessoas e entendem que a força da experiência emocional dos lutos traz alterações para a personalidade.

Não obstante a forma como as pessoas elaboram suas perdas sejam variadas, as tentativas de compreender e poder prestar auxílio a pessoas que passam por processos de luto levaram a uma classificação destes em normal - que seria aquele característico - ou complicado, para os casos em que as conseqüências para a personalidade não são positivas ou que geram inadaptações. Nesse sentido, são Cataldo Neto e Majola (1997, p. 10) quem bem definem o processo de luto normal como: 
... uma síndrome de curso previsível, que inclui reações distintas, como manifestações somáticas, preocupação com o comportamento entre outros. Tal luto descomplicado dura aproximadamente dois anos, sendo minimamente danoso à atividade diária do indivíduo.

A situação de perda é caracterizada por alterações no modo com se lida com o mundo, aqui compreendido como princípio de realidade. Estas alterações podem ser positivas caso levem a pessoa na direção de uma melhor adaptabilidade aos aspectos da realidade sobre os quais ela não tem controle (Heckert, 2002).

É importante ressaltar que o processo de luto não ocorre somente após a morte de uma pessoa, mas a toda mudança que envolve perdas, como as separações conjugais, a saída dos filhos de casa, a perda da saúde, a perda de habilidades cognitivas, de emprego, de condição social, de relacionamentos entre muitas outras que necessitam de elaboração (Cataldo Neto \& Majola, 1997; Heckert, 2000).

Este trabalho buscou compreender a maneira como mulheres saudáveis passaram por situações de perdas e rascunhar uma compreensão de como e se isso se associa ao fato de terem chegado saudáveis à maturidade. Isso quer dizer que se trata de um estudo exploratório que levanta dados qualitativos sobre o tema, que busca uma compreensão dinâmica do objeto estudado.

\section{Objetivos}

O objeto de estudos deste trabalho são mulheres maduras saudáveis, tanto física como psicologicamente. O objetivo geral foi levantar dados sobre a forma como mulheres maduras saudáveis lidam com as perdas que lhe são imputadas pela vida, sejam elas reais ou imaginárias. Dizendo de outra forma, o trabalho investigou a forma como mulheres maduras saudáveis elaboram seus lutos.

\section{Método}

O método utilizado foi o clínico, a partir das falas dos sujeitos em entrevistas abertas sobre a história de vida e da observação durante o contato com as sujeitos que se buscou identificar processos de perda real ou imaginária e a forma como realizaram a elaboração destas. Ou seja, a questão da elaboração dos lutos emergiu do material obtido em entrevistas gravadas sobre a história de vida de mulheres maduras saudáveis.

Os sujeitos da pesquisa foram 3 mulheres saudáveis, fisicamente e psicologicamente, que apresentam boa qualidade de vida, assim como um estado de humor predominantemente condizente (ou seja, de bem-estar), que não apresentam patogenias ou quadros psicopatológicos desadaptadores, sem tendências a quadros depressivos prevalentes - sendo estas as características que nortearam a indicação de seus nomes por um médico geriatra.
Todas elas têm nível socioeconômico médio ou médio-alto; idade acima de 50 anos (duas têm 50 e uma 70); foram ou são casadas (uma delas está num segundo casamento e as outras duas não têm relacionamento afetivo estável no momento, sendo uma viúva e outra divorciada); as três são mães. A padronização dessas variáveis foi buscada para evitar que diferenças pudessem intervir nos resultados. Elas foram discutidas e consensadas com o médico geriatra que indicou os sujeitos.

Mediante as indicações do médico, foram feitos os primeiros contatos com as mulheres por telefone. Nessa ocasião lhes era informado que haviam sido indicadas pelo médico e esclarecidos os propósitos da pesquisa. Das mulheres indicadas, em número de sete, cinco foram encontradas à época (duas estavam viajando) e, destas, três se comprometeram prontamente e marcaram as entrevistas sobre suas histórias de vida.

As entrevistas foram realizadas nas residências dos sujeitos, por um clínico experimentado, e gravadas em fitas de áudio que, posteriormente, foram transcritas integralmente, analisadas como um todo pelo grupo de pesquisadoras e, nessa análise, identificou-se que a elaboração das perdas aparecia como uma questão importante que se evidencia nas narrativas das entrevistadas. Na ocasião, os sujeitos assinaram termo de autorização para gravação, análise e publicação sobre o material, sendo-lhes garantido o sigilo sobre dados que pudessem identificá-las.

A partir disso, o foco de análise foi definido e passou-se a levantar as situações de perda e de sua elaboração descritas por cada uma das mulheres entrevistadas, após o que se procurou encontrar semelhanças e diferenças entre os sujeitos quanto ao aspecto estudado.

\section{Apresentação e Análise dos Resultados}

\section{$1^{\circ}$ Sujeito: Wilma}

Wilma é uma senhora que hoje conta 70 anos de idade e que, quando ainda tinha os filhos pequenos, foi deixada pelo marido, que se envolveu com uma colega de trabalho. Ela criou as filhas e atualmente tem um convívio bastante saudável com elas e os netos, que fazem de sua casa um lugar movimentado e alegre (sic).

Percebe-se neste sujeito uma enorme facilidade e habilidade para aceitar os contratempos e perdas. Ela relata que, durante toda a sua vida, utilizou-se de uma filosofia que cita na seguinte frase:

"Deus escreve o jornal de nossa vida; deixa que sua história seja bela."

E ela complementa:

"Esta frase me fortificou durante a minha caminhada..." 
"Estou sempre adicionando um pouco de amor e de vida há esses anos que eu tenho..., hoje minha vida tá ótima... Fica mais fácil de você viver."

"Então, por exemplo, a coisa ta difícil ta, mas vamos superar e eu superei todas, o que vier tô aí para superar.”

Wilma perdeu sua cidade natal em uma inundação. E desta perda ela relata:

"Perdi minha cidadezinha natal, minha vida simples, a casinha que era simples, as andorinhas, o sino da casa paroquial, a natureza."

"Ah, mais os moradores da cidade ganharam uma nova cidade linda."

A perda da cidade natal para a qual não pode mais voltar, parece estar relacionada à perda da infância que ela só pode re-visitar na memória. A cidade não existe mais! Tudo o que viveu naquele lugar está submerso nas águas, assim como o passado e a infância perdidos estão no inconsciente, ficando na superfície as lembranças que ela coloriu de gratidão e generosidade - acredita que os atuais moradores se beneficiaram com a mudança.

A memória que Wilma tem de sua infância na cidade natal apresenta-se como uma espécie de resgate do passado, que é resignificado, transfigurado. $\mathrm{Na}$ transfiguração "atua uma forma de identificação projetiva em que a percepção do mundo é colorida de uma maneira especial, que altera o observado, elevando-o de seu sentido de crua realidade a outro..." obtendo-se, assim, outros sentidos, novos e mais belos (Melo, 2002, p. 19).

Mas, antes do desaparecimento concreto da cidade de Wilma, na adolescência, ela se mudou de lá para estudar. Também, nessa perda, ela relata os ganhos que teve com a nova morada, reforçando mais uma vez sua capacidade de encontrar os aspectos positivos em suas perdas.

Apesar de ter não sido escolha sua ir para o colégio interno e deixar sua cidade natal, ela vê o lado bom dessa experiência e de tudo o que teve oportunidade de aprender com as freiras: coisas que elevassem o espírito.

"Nossa, mas era uma coisa muito especial, e lá eu fiquei... Peguei uma vivência de lá muito boa."

Nesta mesma cidade, para a qual se mudou, Wilma constituiu família, trabalhou, melhorou de vida e comprou a casa dos seus sonhos. Terminada sua casa, construída para a família que constituiu, teve que mudar logo em seguida para uma cidade próxima, tendo que se desapegar, novamente, de tudo que tinha sonhado e materializado ali.

"E ai nós tivemos que ir, fomos para uma casa até velha, porque não tinha casa melhor para a gente alugar. Mas aí eu vi que não era nada disso que importava. Sabe? O que nós recebemos da nova cidade foi muito mais. Nossa! Foi uma beleza e lá fiquei oito anos e meio."

Wilma elabora a chegada na nova cidade e a perda da antiga enfocando o que tem de bom no novo. Ela se mudou no dia 23 de dezembro, chorando; e no dia 25 já se sentiu aberta para a nova cidade, o que demonstra sua capacidade de elaboração de mudanças, arcando com as conseqüências do luto, realizando o fechamento das situações perdidas para recomeçar as novas, se disponibilizando a ver os ganhos que decorrem das mudanças. Ela não se priva do direito de sofrer, chorando suas perdas, mas não se detém nelas.

Mais tarde, antes de voltar à cidade em que morava anteriormente, Wilma separou-se do marido. Na perda, com certeza dolorosa, principalmente por ter sido repentina, contou, segundo ela, com a ajuda dos amigos, colegas e filhas.
"Mas aí quando eu voltei, eu já tava sem meu esposo, porque ele tinha dado tchau”.
"Mas aí foi bom, aí eu vi que eu tinha mesmo uma força interior.”
"Eu arranjei uma resistência que eu não sei de onde que ela veio não, mas ela veio, veio e foi bom, porque a gente vai mudando..."
"Eu vi que a vida é amizade, a força que Deus dá pra gente, mesmo, interior, sabe? Você busca lá dentro, aquela força, sabe? A gente consegue tudo, não pode vacilar, mas consegue, e eu tenho conseguido até hoje."

À primeira vista, quando fala que seu "marido deu tchau" quando se separaram, Wilma parece estar banalizando a situação que, com certeza, foi dolorosa. Mas, no decorrer de sua história e diante da narrativa de outras perdas, isso parece se referir mais ao fato de usar mecanismos que a permitem elaborar a raiva pelo abandono. Isso poderá ser observado adiante, quando fala da morte da mãe.

O "dar tchau", atribuído ao marido, imputa a ele a decisão de ir embora e de sair de sua vida. Nesse caso, cabia a Wilma lidar com o abandono e elaborar mais um luto, já que a imagem desse marido, que trai e abandona, se quebrara. Nessa fase de sua vida, sua capacidade de se recompor, de restaurar sua autoestima e construir a vida sobre novas bases é colocada à prova.

A "força interior", a "resistência" que só puderam ser descobertas por ter tido que enfrentar a dificuldade transformou sua personalidade, aprimorando-a, deixando mais integrada e autoconfiante de suas capacidades.

Um fator que ajudou na superação desta fase foi o investimento na espiritualidade. Encontrou suporte e alento na religião. Relata que, nas reuniões religiosas, pôde sentir "um bem estar muito grande", que propiciou que encontrasse, dentro de si mesma, a crença e a fé, que continuaram fortalecendo-a nos momentos difíceis, até hoje. 
Após a separação, não quis se envolver com outra pessoa, dedicou-se à família e quando o marido quis voltar, após dois anos, ela não quis mais. Entretanto, tornou-se muito amiga dele, mostrando capacidade para perdoar.

"Eu não guardo mágoa, aconteceu é por que tinha que ser assim."

A amizade com o ex-marido, que se mantém até hoje, é descrita como uma relação de ajuda e compaixão mútuas. Assim, a decisão de não retornar ao casamento parece referir-se a uma decisão de vida norteada não pela raiva causada pela dor, mas a uma opção, provavelmente pautada na experiência que teve chance de experimentar após a separação, que a levou a se sentir mais dona de si e mais forte. A experiência de elaboração da perda parece tê-la oportunizado entrar em contato com aspectos de sua personalidade antes desconhecidos.

Wilma aposentou-se para se dedicar mais à família, principalmente para cuidar dos netos, e aposentou-se cedo, ainda jovem, não tendo problemas para enfrentar tal mudança, pois esta lhe traria ganhos no convívio com os seus. Mas essa mudança parece ter sido tranqüila, também, porque não significou estagnação. Valorizando sempre as amizades e a família, começou a participar de um grupo de senhoras - o que mostra uma postura ativa e desejo de integração e de se sentir útil.

Wilma considerou como perdas mais difíceis as de seu pai e sua mãe.

"Aí meu Deus, você sabe que eu sou uma pessoa assim... que dificuldade mesmo, que eu achei, mesmo, foi só perder meu pai e minha mãe, esta foi a maior tristeza que eu tive, porque meи pai é uma pessoa assim muito simples e ele, meu pai, era uma pessoa desprendida de tudo, de tudo mesmo... Então foi dificil dar tchau para ele."

Segundo Wilma, ela enfrentou a perda trabalhando, ocupando a cabeça. Conserva do pai, e reconhece como característica internalizada em si mesma, a simplicidade, o desprendimento e o gosto pela cultura.

Da mãe, de quem cuidou por 14 anos, até que viesse a falecer, Wilma assume ter como herança psicológica o amor pela vida, a alegria e o gosto pela beleza. Descreve, por exemplo, quando a mãe, já doente, pedia a ela que a levasse até o varal para que pudesse sentir o cheiro das roupas lavadas - o gosto pelas coisas simples a caracterizava. Também da mãe vem a "garra de trabalho" e o investimento maciço na família, segundo ela.

O reconhecimento das características do pai e da mãe, internalizadas, pode ser pensado como formas de mantê-los vivos em si mesma, como uma maneira usada por ela para se reconciliar com a perda e manter seus objetos internos intactos em seus pontos positivos.

Quanto à perda da mãe, fala do tempo que teve que cuidar dela e na extensão de sua perda:
"Foi difícil porque mamãe tinha uma presença muito forte, muito marcante, morreu forte amando a vida."

Wilma, em suas palavras, transpôs as barreiras com: "Força, coragem, fé religiosa, com amor,
perdoando sempre... A luta foi boa."

Wilma afirma ter aceitação, inclusive, da própria morte, pois esta é inerente à vida e, por isso, deve-se aceitá-la:

"Não tenho medo de morrer... Então eu tô aqui, e na hora que me chamar eu to presente, não tem essa de ficar segurando sabe... Então tudo que vier daqui pra frente é acréscimo, por isso eu só quero coisas boas."

"Estou desprendida já... o que vier é acréscimo, nada foi de graça, foi luta mesmo e isso agrega valor às conquistas. Eu acho que a tristeza não leva a nada."

O desejo de ser útil, o esforço para vencer e para afastar a solidão estão associados à sua capacidade de superação e elaboração das perdas.

"A gente tem que ser forte, mais com alegria né."

"É uma luta, né? Mas é uma luta gostosa? Que cê vai passando,... Fala pô venci! Que bom! Vamos encarar a próxima."

O desprendimento, a visão de que a felicidade está nas coisas simples, o gosto pela vida e pela beleza aparecem de forma marcante, em Wilma - como ela mesma afirma. Isso se evidenciou, também, na sua relação com a arte. Na juventude e princípio da idade madura, fez rádio-teatro, representou, escreveu peças.

Wilma tem uma capacidade de transfigurar a realidade, transpondo a realidade para um outro patamar. Na transfiguração,

... o percebido recebe novos sentidos que vêm servir à construção de uma realidade mais bela e intensa cujo efeito para o transfigurador é por um lado a elevação do eu, a alimentação narcísica do criador $e$, por outro, um alívio para que suporte tudo o que percebe, tendo em vista sua sensibilidade. (Melo, 2002, p. 19)

\section{$2^{\circ}$ Sujeito: Ângela}

O principal aspecto observado em Ângela foi a forma gradativa com que ela enfrenta as perdas e as adversidades da vida. Tudo o que vai lhe trazer mudanças, ou as situações difíceis que tem que enfrentar, ela administra de uma maneira que possa usar um tempo para se preparar. Isso pode ser associado a situações que a vida lhe apresentou, como se poderá perceber adiante, e parece ter sido adotado por ela como uma estratégia de enfrentamento.

A partir das perdas que ela sofreu, que foram todas graduais, ela aprendeu uma forma de enfrentar as situações difíceis. Trabalha, ocupando a cabeça, ajuda 
a família, busca na arte e no artesanato uma ação terapêutica e está sempre buscando aprender com a experiência. Além disso, demonstra muita aceitação para com os acontecimentos da vida.

"O que vem pra gente, o que acontece com a gente, eu acho que é muito melhor a gente aceitar e tentar resolver do que a gente ficar aí revoltado..."

Para Ângela, é necessário estar sempre se preparando para os acontecimentos que exigem mudança em sua vida, o que pode ser visto nas seguintes frases:

"Tudo que eu tenho que fazer... que vai trazer uma diferença me preparo para aquilo."

"Eu não gosto nada de que é tudo resolvido de um dia para a noite, eu gosto é assim: das coisas que quando vão acontecer, que venham assim, já com a cabeça amadurecida para aquilo, é um sistema que eu tenho."

Ângela procura sempre uma forma de adiar os acontecimentos que vão lhe trazer mudanças, para que possa se acostumar com o novo, inclusive quando necessitava passar por algum processo cirúrgico (até hoje essas foram simples e sem gravidade), ela se preparava bem antes. Segundo ela, esta maneira de lidar com mudanças a tranqüiliza.

A primeira perda que ela relata foi a morte do avô, que morava com ela e a família; relata que sua mãe cuidou dele por muitos anos. Na segunda, seu pai foi acidentado quando ela era uma adolescente jovem e faleceu quando ela tinha pouco mais de vinte anos. Durante este período, ele permaneceu na cama, devido a vários erros médicos; quem cuidou dele foi a mãe. Nesse tempo, Ângela conviveu com a morte a cada dia, elaborando a perda gradativamente.

Ângela casou-se e teve três filhos. Seu marido logo adoeceu, vítima de uma doença degenerativa; permaneceu doente por nove anos. Ela o acompanhou em várias cirurgias, durante o tratamento, e cuidou dele por todo esse tempo.

\section{"Foram nove anos de operações e tratamento."}

Depois da morte dele, Ângela teve que assumir os negócios da família, a respeito dos quais ela não tinha nenhum conhecimento. Então ela procurou o sogro para ajudá-la, mas dois meses depois ele também faleceu. Assim, ela teve que procurar aprender sozinha. Sempre enfrentando as dificuldades com aceitação.

"Não é querendo achar que aquilo não ta certo, que não era pra acontecer, que alguém tem culpa, porque eu estou sofrendo mais que os outros, é uma característica minha de entender que a vida não é igual para todo mundo."

"Os negócios tava tudo em comum com meu sogro e minha sogra... Mas logo em seguida que meu marido morreu, o meu sogro morreu dois meses depois, e era ele que tava dando apoio e me passando tudo que eu precisasse."

No enfrentamento da nova situação, em que decidiu assumir os negócios, Ângela procurou aprender e o fez a partir da experiência e sempre de forma também gradual.

“Eu passei a ir para.......... [local em que tinha negócios], ficava mais lá... assim... aprendendo, vendo como era o dia-a-dia..."

A aprendizagem de que mudanças exigem tempo para sua elaboração parece ter partido das experiências de morte ao seu redor. Os lutos anunciados puderam ser elaborados de maneira gradativa $\mathrm{e}$ foi isso que ela aprendeu com a experiência.

Ângela assumiu a tarefa de cuidar do marido sozinha, sem ajuda de enfermeira. Parece haver, com relação a isso, resignação e um gosto em se sentir útil, em cumprir aquilo que assume como seu dever.

Esse senso de dever, Ângela assume como uma herança psicológica por parte de sua mãe, pois esta sempre cuidou das pessoas, cuidou do sogro e depois do marido.

Do pai, Ângela diz ter herdado o lado sério de ser.

"Meu pai era muito sério, reservado ele era muito...
levava a vida muito a sério, os negócios ele
separava muito."

Ela relata que sempre se ocupou com outras atividades, o que diz tê-la ajudado a superar os problemas: os trabalhos com as mãos, o artesanato.

Como as perdas que ocorreram em sua vida aconteceram devagar, Ângela teve tempo para elaborar seus lutos e parece ter sido capaz de transpor esta experiência para outros aspectos da vida, aprendendo a ter aceitação.

Um ano após a morte do marido, ela começou a ter um novo relacionamento amoroso. Tendo aprendido que precisa de tempo para adaptar-se a situações novas, mesmo tendo elaborado a perda do marido, ela pediu um tempo àquele que seria seu segundo marido, para se preparar para as mudanças que resultariam da nova união.

\footnotetext{
"Porque foi tudo assim muito gradativo, e eu tudo que eu tenho que fazer, que é mais assim, que possa me trazer como se diz, uma diferença que vai mudar minha vida, alguma coisa que eu sempre assim me preparo para aquilo, então quando o meu novo marido falou da gente morar junto, eu falei bom, me dá um tempo."

"Então eu queria, assim, que fosse uma coisa com calma para meus filhos também irem se adaptando... mas eu acho que foi uma coisa assim... o meu filho almoça comigo todo dia, minha filha ta sempre aqui."
} 
Ou seja, ela utiliza a mesma estratégia para que as pessoas à sua volta também se adaptem às novas situações. Preparou-se para a saída dos filhos, também de forma lenta. Ela diz que não sente que os filhos foram embora. Está sempre por perto e ajudando-os em tudo que é necessário. E ela repete a expressão em todos os momentos em que fala de mudanças e perdas, ainda que elas envolvam ganhos:

\begin{abstract}
"Foi tudo assim muito gradativo."
"Meu filho mais novo, ele quis cuidar............. [dos negócios], ajudar... Há pouco tempo o do meio tá morando sozinho numa casa que nós compramos, a minha filha também mora com o marido em outra casa tudo aqui pertinho de mim... e eu dando assistência a tudo, arrumei empregada pra ele, vou lá, ajeitei, arrumei a casa dele."
\end{abstract}

Outro fator que Ângela diz que a ajudou superar as fases difíceis de sua vida, foi a questão da fé, apesar de não ter religião específica, ela sempre reza e pede ajuda espiritual.

"Eu não freqüento igreja mais eu tenho muita fé...
eu sou católica, mas acredito no espiritismo, eu
fiquei no meio, não decidi ainda."
"Acho que o espiritismo é mais viável, mais
acreditável então eu misturo."
"Eu tenho um santo que eu gosto muito, ele é
brasileiro e me ajudou muito na doença do meu
marido eu sempre me recorro a ele."
"Eu rezo todo dia, mas freqüentar a igreja só
quando tem missa de sétimo dia."

Assim, pode-se dizer que a característica mais marcante do processo de elaboração de perdas de Ângela é o enfrentamento gradual das mudanças, que ela provoca sempre que possível - e a vida tem lhe proporcionado essa possibilidade. Soma-se a esta característica, a reparação, que realiza no cuidado, com as pessoas à volta (como dos filhos, por ocasião do novo casamento e nos cuidados com o marido durante a doença). Essa reparação parece marcar também seu gosto pelo artesanato, que aparece como uma possibilidade simbólica de fazer, com suas mãos, coisas belas.

\section{$3^{\circ}$ Sujeito: Clara}

Dos processos de perda que Clara descreveu durante a entrevista de história de vida, a morte do marido foi a mais marcante. As mudanças de cidade, a separação do marido por causa do trabalho dele, o crescimento das filhas, a perda do pai, são outras que também puderam ser identificadas.

Clara considera que, através dos fatos indesejáveis que ocorreram em sua vida, pôde tirar proveito, aprendendo, inclusive, a preparar-se para as próximas perdas.

O marido trabalhou por um tempo em outra cidade e ela conta que chorou na rodoviária, várias vezes, ao despedir-se dele; mas, com o tempo, acostumou-se e considera que, assim, aprendeu a preparar-se para mudanças futuras.

Clara mudou de cidade várias vezes, em função do trabalho do marido. Segundo ela, as primeiras mudanças foram mais difíceis e que também se acostumou a isso. Considera, inclusive, que as mudanças foram boas para suas filhas, pois elas também tiveram a oportunidade de aprender. Percebe, assim, os aspectos positivos de uma situação difícil para todos.

Ao que tudo indica, Clara transpôs esta experiência para outros aspectos da vida:

"A primeira mudança foi mais difícil, muito dolorosa, depois vai se tornando mais fácil, se acostuma."

"No começo chorava na rodoviária, chorei, chorei."

Segundo sua própria opinião, a "lamúria" só a fazia sofrer. Então procurou novas atitudes e conseguiu resultados mais positivos. Tentou extrair da dor um aprendizado benéfico.

\begin{abstract}
"Acho que foi bom, na época talvez não, mas depois com o andar dos acontecimentos eu vi que foi muito bom, preparo pra mim, para meninas, né! Acho que foi um preparo."

"Nesses pedaços de mudanças, escola, adaptação... tudo bem."
\end{abstract}

Com o passar do tempo, devido às constantes mudanças, Clara adquiriu um novo estilo de vida. $\mathrm{O}$ que, no passado, causava-lhe uma certa angústia, hoje é considerado como um fato determinante em sua vida. Segundo ela, isto lhe facilita viver - reforçando mais uma vez sua capacidade de adaptação e aceitação de uma situação nova que requer desprendimento da anterior.

"Então, eu acho que eu sou assim, depois das mudanças, eu nunca mais gostei muito de ter um lugar, uma coisa só."

As permanentes mudanças em sua vida levaram-na a querer sempre se renovar. Sua certeza mais estável passou a ser sua disposição para o novo.

"É um tipo meio nômade. Eu acho que isso me facilita muito, a viver..."

A luta, as permanentes perdas ensinaram-na a renunciar em favor de outrem.

\section{"Saber abrir mão das coisas."}

A aceitação para com os fatos da vida, por Clara, tem como exemplo relevante, a ser citado, a forma como lidou com a morte do marido, do qual ela cuidou por três anos de doença, pois este possuía uma doença degenerativa. 
Ela parecia suprimir os pensamentos conscientes a respeito da perda iminente e, assim, evitou compartilhar as informações sobre a doença do marido com os familiares. Não gostava de comentar ou conversar sobre o assunto nem sequer com as filhas. Esta atitude de Clara, aparentemente, foi tomada para minimizar o sofrimento das pessoas próximas, mas refere-se também à sua própria evitação de ter que entrar em contato com a perda, antes que ela ocorresse.

Esta evitação sugere um mecanismo de defesa de negação, de maneira que, não falando sobre o assunto, não teria que entrar em contato com ele. Clara racionaliza isso afirmando que se tratava de uma responsabilidade sua e que, por isso, não dividia os problemas com as pessoas.

Embora tenha se arrependido de não ter compartilhado as dificuldades vividas com a doença do marido sequer com a família dele, os mecanismos por ela adotados foram eficazes para que pudesse superar aquela fase de forma saudável: quando o marido falece, ela se percebe tendo feito tudo o que lhe era possível fazer para ele.

Naquilo que era necessário, ela conseguiu lidar com a situação, pois relata que sempre quis saber tudo sobre a doença e procedimentos médicos, mas guardava para si. Clara assumiu a responsabilidade da doença do marido como algo que "veio" para ela "cuidar e amparar" e via isso como uma "obrigação" somente sua. Como pode ser observado na seguinte frase:

"É assim, tava lidando com aquele negócio e parece que a obrigação era minha e eu tinha força dobrada."

A realidade da perda que viria, inevitavelmente, foi sendo trabalhada, elaborada gradativamente. A cada lapso de tempo que acontecia, em cada perda imputada ao marido, ia fortalecendo sua a capacidade de ajudar e auxiliando-a na sua própria elaboração da perda. Aqui, o "cuidar" aparece também como uma possibilidade de reparação, de modo que teve tempo para se reconciliar com esse marido em todos os aspectos, pois fez aquilo que deveria ter feito para ajudá-lo na fase terminal.

"O dia que ele ia ao médico dele... eu ia levar os exames e o médico falava tudo, mas um, dois meses para frente, sobre o que iria acontecer."

"A cada dia cê convivia com a morte. Foram três anos e meio de doença."

Uma outra forma que Clara utiliza para aceitar os contratempos da vida é não ficar reclamando da situação. Acredita que a melhor maneira de superar um momento difícil é fixar-se na idéia de que isso vai passar, não ficar esperando ajuda de outras pessoas, ter suas próprias iniciativas e atitudes. Assume para si o fardo colocado em seus ombros e carrega-o com resignação e fortaleza. O otimismo a faz acreditar num amanhã melhor, mais positivo.

\begin{abstract}
"Quando a coisa tá ruim, tá triste, então aquilo passa um dia, dois dias e passa."
\end{abstract}

$\mathrm{O}$ que se extrai de suas atitudes são iniciativa e garra. Não se coloca na posição de vítima, aguardando apoio, mas procurar resolver, como pode, a situação na qual se encontra. Tira disso um ganho narcísico e uma maior confiança nas suas próprias capacidades.

\begin{abstract}
"Eu acho que é esse tipo de não ficar reclamando, de não ficar lamuriando, de não ficar deitado esperando alguém vir passar a mão na minha cabeça até eu levantar. Vai fazer o que tiver de fazer, acho que não pode deitar, não pode esperar."

"Vai atrás de outras coisas, aquilo ali vai passar, vai demorar um dia, dois, uma semana, mas aquilo ali vai passar."
\end{abstract}

Outra característica de Clara é que está sempre ocupando a cabeça, seja com o trabalho ou com a arte manual. Relata que tem muita fé religiosa e que isto também a ajuda passar por momentos difíceis de sua vida.

Percebe-se que Clara aprendeu com as experiências que lhe foram proporcionadas pela vida. Das mudanças e do tempo em que seu marido morou longe dela, aprendeu a lidar com as situações da vida por si mesma e ganhou autoconfiança, pois aprendeu que, mais do que lamentar e esperar que a ajudassem, podia se superar e assumir o que tinha que ser feito.

As pequenas perdas, ou situações que requereram enfrentamento por sua parte, foram o pano de fundo para o fortalecimento de seu equilíbrio emocional representaram um ganho narcísico que Clara aprendeu a reconhecer e que a alimentou nas dificuldades que se seguiram.

Assim, Clara é uma pessoa que está sempre à busca de uma atividade que lhe oferece ocupação e satisfação.

\footnotetext{
"Não dou corda pro que é ruim, é indo à luta né, fazendo outra coisa, ocupando o tempo, ocupando a cabeça."
}

Clara não se refugiou em condição alguma para superação de suas perdas. Buscou arregimentar forças no próprio meio, mesmo adverso. $\mathrm{O}$ trabalho e o sentimento de utilidade foram coisas das quais ela lançou mão para superar as adversidades:

\begin{abstract}
"Mesmo não trabalhando fora, eu nunca fiquei parada. Todo dia eu tinha o corpo cansado, eu deitava e dormia..."

"Eu acho que o trabalho, eu acho que a pessoa não pode ficar parada."
\end{abstract}

Ela não se circunscrevia ao meio, mas procurava romper com as limitações e adversidades. 
"Não pode ficar limitado só dentro de uma casa, fazendo só aquilo, precisa ampliar os interesses, fazer outras coisas."

Clara sempre buscou, também, fortalecer-se na fé. A crença em algo além do material, o investimento religioso, parece ter-lhe servido de apoio:

"Tive sempre um investimento religioso, espiritual! Eu acho que o espiritual é muito importante.... Tô sempre lendo livro espírita...."

Também este sujeito apresenta como característica a busca religiosa, a dedicação a atividades ligadas aos trabalhos manuais e o investimento no trabalho, numa ocupação.

\section{Discussão dos Resultados}

Após a análise das entrevistas, percebe-se que as três mulheres investigadas atingiram a maturidade saudável lidando de maneira peculiar com as experiências da vida, ou seja, apresentam diferenças na qualidade do princípio de realidade. $\mathrm{O}$ interesse, diante da riqueza do material fornecido pelos sujeitos, recaiu sobre o modo como elas viveram as perdas por que passaram na vida e a maneira como elas foram elaboradas, descritas espontaneamente durante as entrevistas sobre a história de vida.

Wilma afirma que enfrentou as perdas valendo-se sempre de uma frase que ouviu de uma madre no colégio em que estudava, em um momento difícil, que a fortificou durante sua caminhada e se estendeu como sua filosofia de vida, que diz: "Deus escreve o jornal de sua vida, deixe que sua história seja bela". Isso reforça a maneira saudável que ela possui de elaborar as adversidades da vida, aceitando e transfigurando a realidade, sempre se apoiando nisso.

Wilma acredita que os acontecimentos vêm para serem superados e que é preciso estar sempre preparado para os próximos. Ela parece fazer isso encontrando beleza nas experiências vividas, mesmo nas suas perdas, pois desenvolveu uma capacidade de recriar aquilo que foi perdido num outro patamar. Ela é uma pessoa criativa, nesse aspecto e em outros (que aqui não encontram espaço de discussão). Apresenta um modo transfigurativo de lidar com a realidade que: “... pode ser pensado como uma forma especial de reversão de perspectiva em que o sistema dedutivo científico é preterido em favor de uma opção estética" (Melo, 2002, p. 164).

As perdas sofridas por Wilma, que, com 70 anos de idade, tem uma história de vida muito rica, foram como que re-escritas por ela. O sofrimento é transformado em glória, os aspectos positivos da experiência são valorizados. No contato com o entrevistador, ela se mostra uma pessoa radiante de vida, cheia de energia e disposta a gozar suas relações e seus momentos de prazer - que busca ativamente nas atividades que planeja, tais como viagens com os netos, excursões, dança, reuniões de senhoras, trabalho assistencial.
Ângela aprendeu a elaborar tudo gradativamente, mas não significa "adiamento", o que seria um tipo patológico de luto. Ela encontrou uma maneira de se preparar para as mudanças. Isso porque a vida apresentou a ela estas chances, soube aproveitá-las e aprender com estas uma forma que aplicou e estendeu às mudanças de sua vida. Parece que, na verdade, o que Ângela aprendeu foi a antecipar a elaboração das mudanças e dentre essas, as perdas. Assim, pôde aceitar cada uma delas e hoje busca trabalhar internamente seus objetos, a fim de viver os lutos e mudanças de forma gradual. A ambivalência inerente a todas as situações de mudança parece ser resolvida ao nível da elaboração imaginativa e essa é a maneira pela qual a entrevistada se prepara para a realidade da mudança.

Esta maneira de lidar com a realidade, não significa que Ângela não se relacione com os objetos do mundo compartilhado. Parece aplicar-se a ela o enunciado central da tese de Winnicott (1994, p. 174) sobre a passagem do relacionamento com os objetos ao uso dos objetos operado pelo humano na construção do mundo compartilhado:

essa coisa que se situa entre o relacionar-se e o uso é a colocação, pelo sujeito, do objeto fora da sua área de controle onipotente, isso é, a percepção que o sujeito tem do objeto como fenômeno externo, não como entidade projetiva, $e$, na realidade, o reconhecimento dele como uma entidade por seu próprio direito.

A mudança, a perda e mesmo os ganhos são vividos por Ângela, primeiramente com o auxílio de sua função imaginativa e é assim que prepara-se para a assimilação de sua realidade.

Clara apresentou ter características semelhantes tanto às de Wilma quanto às de Ângela, pois também possui uma boa capacidade de aceitação, aprendendo de forma gradativa, devido às perdas que a vida lhe impôs, como, por exemplo, a doença degenerativa do marido, assim como a morte dele; além de estar sempre tendo que mudar de cidade, devido ao trabalho do marido. Através dessas mudanças, Clara adotou um novo estilo de vida, no qual se adaptou muito bem, como pode ser visto na seguinte frase: "É um tipo meio nômade. Eu acho que isso me facilita muito a viver".

O que aparece como um aprendizado bastante marcante é sua capacidade de suprimir da mente aquilo que não pode ser mudado, para que, internamente, seus objetos e cenário possam ser reestruturados e restaurados em seus aspectos bons.

Em Clara a elaboração aparece com certa semelhança em relação à Ângela, pois o trabalho elaborativo se realiza em seu mundo imaginativo, até que a perda se concretize e possa ser aceita. Enquanto isso parece usar do mecanismo de reparação, cumprindo aquilo que pensa ser sua obrigação - que, nela, fica mais evidente do que nas outras - o que não significa que elas não o apresentem; pelo contrário, está presente em todas elas, de forma peculiar. 
A reparação aparece nos três sujeitos; em Clara se evidencia no trabalho voluntário realizado em asilos e no sentido de resignação que assumiu diante de adversidades. Resignação, aqui, não é entendida como sinônimo de estagnação, mas de aceitação das dificuldades e da assunção de tarefas que podem levála à sensação de dever cumprido - ou seja, de que se conciliou com aspectos negativos / agressivos presentes nas relações ambivalentes.

A transfiguração que se evidencia em Wilma, especialmente por sua forma de expressão verbal, marcada pela alegria transbordante, que revela sua gratidão e criatividade, é também característica das outras duas entrevistadas. Entretanto, naquelas, as personalidades não foram tão marcadas por essa característica, mas sua lida com a realidade sim. Ambas dedicam-se à realização de trabalhos manuais, em gerar beleza com suas próprias mãos.

As três mulheres saudáveis, cujas vidas não foram absolutamente fáceis ou desprovidas de desafios, mas ao contrário, marcadas de situações de perda e mudanças desafiantes e dolorosas, demonstraram ter de-

senvolvido modos transicionais de funcionamento plenos, ou seja, daqueles que a permitem viver num mundo intermediário e, ao mesmo tempo, obter aprovação e até valorização social. A explicação dessa possibilidade de funcionamento vem de Winnicott (1990, p. 127):

Entre o subjetivo e aquilo que é objetivamente percebido existe uma terra de ninguém, que na infância é natural, e que é por nós esperada $e$ aceita. $O$ bebê não é desafiado no início, não é obrigado a decidir, tem o direito de proclamar que algo que se encontra na fronteira é ao mesmo tempo criado por ele e percebido ou aceito no mundo, o mundo que existia antes da concepção do bebê. Alguém que exija tamanha tolerância numa idade posterior é chamado de louco. Na religião e nas artes vemos essa reivindicação socializada, de modo que o indivíduo não é chamado de louco e pode usufruir, no exercício da religião ou na prática $e$ apreciação das artes, do descanso necessário aos seres humanos em sua eterna tarefa de discriminar entre os fatos e a fantasia.

O gosto pelas produções artísticas e a religiosidade são marcantes nas três mulheres saudáveis investigadas.

Outro ponto a ser assinalado nessas mulheres é a "tolerância à frustração" e a "continência". Para Bion (1994, p. 129), "a capacidade de tolerar frustração (...) possibilita que a psique desenvolva o pensamento como um meio através do qual se torna mais tolerável a frustração que for tolerada". Assim, tolerar a frustração favorece o advento e desenvolvimento do pensamento e que o pensamento, por sua vez, favorece a capacidade de tolerar frustração, num funcionamento típico do princípio de realidade.

Essa característica acima aparece de forma bastante clara nas três mulheres estudadas, em oposição às características de quem não tolera frustração, ou seja, a adoção de "mecanismos que acenem com a promessa de solução instantânea para os problemas suscitados pela existência de emoções não-desejadas" (Bion, 1994, p. 98).

Pode-se pensar que essa capacidade de pensar foi o que possibilitou a elas vencer as dificuldades e, apesar delas, carregar os filhos na direção da melhor resolução possível. Todas passaram por acontecimentos difíceis e não foram poupadas pela vida; ao contrário, tiveram maus momentos e exigências a superar.

Nas três mulheres, a lida com o tempo, com a espera necessária, está presente. Percebe-se uma capacidade que elas possuem de encarar as perdas como algo que é inerente à vida, cabendo a elas aceitar e adaptar-se à nova situação. Isso não significa que não sofreram ou sofrem, mas que estão de acordo com a vida naquilo que não lhes cabe ou é possível mudar. A continência traduz algo mais do que a palavra aceitação.

A continência é bem definida por Rezende (1993, p. 233) como:

\begin{abstract}
... o lugar da transformação. A continência é acolhedora e transformadora. $O$ que faz a continência é a nossa capacidade de acolher, com paciência mas também com segurança, da segurança para a continência acolhedora, da continência para a receptividade ativa.
\end{abstract}

Assim se apresentam as mulheres estudadas: não desanimaram diante das adversidades, mas buscaram superá-las, acolhem as coisas que a vida lhes apresenta e passam por elas adquirindo cada vez mais segurança para lidar com os próximos enfrentamentos.

As entrevistadas tornaram-se capazes de enfocar o lado positivo de suas perdas, o que não significa que não tenham sofrido, mas que aprenderam a lidar com os aspectos agressivos da experiência e, assim, conseguindo aprender e amadurecer com a situação difícil.

Heckert (2002) diz que, após a perda, pode ocorrer uma preparação de um novo modelo de mundo e que, durante esse processo de elaboração, é necessário que se tenha suporte emocional. Como suporte emocional, pode-se compreender o apoio de pessoas em torno como um Ego suficientemente forte para que se possa sustentar a si mesmo emocionalmente. Provavelmente, as duas coisas são fundamentais no processo de elaboração das perdas. Acontece que, no caso das mulheres, elas não só tinham que suportar e superar as perdas, como tinham seus filhos para amparar e acompanhar no processo de luto, que também era deles - especialmente na perda dos pais/marido. Em dois dos sujeitos a perda foi real e em outro, por separação e mudança.

Ao enfrentarem os lutos, elas tinham que entrar em contato com elas mesmas e buscarem uma melhor alternativa para saírem da situação de forma integrada, buscaram forças para si e para amparar os seus. Assim, parecem ter adquirido maior conhecimento de si próprias e de seus sentimentos, tornando-se cada vez mais autônomas em suas atitudes e, conseqüentemente, mais confiantes e seguras para 
enfrentarem com maturidade os contratempos da vida, de forma saudável.

Alguns pontos sobre as três entrevistadas devem, ainda, ser assinalados como indicativos de sua saúde e sucesso na elaboração das perdas, notadamente sua produtividade, fé e religiosidade.

Percebe-se que todas procuram se sentir produtivas, trabalhando e sempre realizando alguma atividade que lhes proporcionam prazer, como, por exemplo, a arte manual, dança, fé religiosa, viagens, entre outros. O subterfúgio utilizado para superação das perdas foi saudável, o que lhes proporcionou novos horizontes.

Um outro fator comum e relevante entre elas é a fé religiosa, embora não sigam apenas uma religião, mas adotem o catolicismo e o espiritismo. Segundo Bianchi (1991, p. 68) aqueles que possuem fé parecem reagir de forma mais positiva à dor e aos lutos. Neste estudo, a religiosidade parece ter sido um fator que forneceu auxilio aos sujeitos na superação das perdas, aparentemente funcionando, em algumas vezes, como um "colo" e, em outras, como uma possibilidade de explicação para os fatos da vida.

Para alguns, a descoberta de poder sobreviver e desenvolver-se, após ter passado por uma grande perda, fortifica o caráter, oferece noção de maior valor de si mesmo (auto-estima) e dá condições para que se viva com mais tranqüilidade do que antes. A saúde e a felicidade aparecem, então, como um resultado, uma conseqüência. Nas palavras de Lowen (1982, p. 30): "a felicidade é a consciência do crescimento".

\section{Conclusões}

Uma forma de elaboração bem sucedida dos lutos foi observada nas três mulheres saudáveis investigadas e parece estar associada ao seu crescimento e amadurecimento pessoal, assim constitui-se em fator na construção da personalidade e na preparação para os enfrentamentos que a vida impõe.

Conforme as perdas vão sendo elaboradas, ocorre o fortalecimento do Ego e a experiência elaborada de forma positiva, bem sucedida, funciona como uma alavanca para o crescimento. Isso se traduz em mais força e segurança pessoal, ou seja, em auto-estima. As mulheres demonstraram ter consciência de suas limitações tanto quanto de sua força, ou seja, de sua capacidade de superar obstáculos.

Pode-se perceber que a passagem pelo luto de forma saudável, ou seja, normal, trouxe a possibilidade de re-significação das perdas, o apaziguamento de aspectos negativos inerentes à ambigüidade que elas imputam, e possibilitou a formação de novos vínculos, provavelmente em função de uma maior integração da personalidade em seus aspectos negativos e positivos.

Fatores comuns de enfretamento entre as mulheres saudáveis estudadas podem ser apontados e parecem relacionar-se com esses ganhos. São eles, especialmente, a capacidade de reparação, o contato com aspectos belos da realidade e a possibilidade de que sejam, também, autoras de beleza (através de vivência transicional e simbólica), o sentimento de utilidade para os outros à sua volta e a religiosidade.

Este estudo, que teve como objeto mulheres, teria no estudo de indivíduos do sexo masculino um termo de comparação interessante, tendo em vista o papel social diferenciado para cada um dos gêneros. As mulheres estudadas mostram-se preponderantemente voltadas para aspectos pouco comuns no homem, como a ligação com trabalhos manuais, a preocupação com a prole e com serviços de caráter altruístico em instituições de caridade e de caráter religioso.

Outras questões suscitadas a partir desse estudo sugerem outras pesquisas, tais como: um estudo comparativo entre o modo de elaboração das perdas entre mulheres maduras saudáveis e mulheres que desenvolveram patologias; um estudo mais detido sobre a elaboração das perdas iniciais na infância e sua influência na elaboração de lutos na maturidade em mulheres saudáveis.

\section{Referências}

Bianchi, E. C. (1991). Espiritualidade do envelhecimento. Em G. H. Rodríguez, D. Callahan, W. J. Burghardt, I. Gebara \& B. Bujo (Orgs.), A Terceira Idade (pp. 68-76). Petrópolis: Vozes.

Bion, W. R. (1994). Estudos psicanalíticos revisados. Rio de Janeiro: Imago.

Cataldo Neto, A. \& Majola, R. R. (1997). O luto normal, o luto patológico e o médico. Revista de Medicina da PUCRS, 7(1), 9-16.

D'Andrea, F. F. (1997). Desenvolvimento da personalidade (13 ${ }^{\mathrm{a}}$ ed.). Rio de Janeiro: Bertrand Brasil.

Freud, S. (1980). Formulações sobre os dois princípios de funcionamento mental (pp. 277-290). Edição Standard Brasileira, vol. XII. Rio de Janeiro: Imago. Publicado originalmente em 1911.

Giusti, E. (1987). A Arte de Separar-se (4 $4^{\mathrm{a}}$ ed.). Rio de Janeiro: Nova Fronteira.

Lino-Silva, M. E. (1990). A possibilidade de criar. Estudos de Psicologia, 7(2), 54-72.

Lowen, A. (1982). Bioenergética ( $9^{\mathrm{a}}$ ed.). São Paulo: Summus.

Melo, S. A. (2002). A transfiguração criativa da realidade. Rio de Janeiro: Sotese.

Rezende, A. M. (1993). Bion e o futuro da psicanálise. Campinas, SP: Papirus.

Winnicott, D. W. (1990). Natureza Humana. Rio de Janeiro: Imago.

Winnicott, D. W. (1994). Sobre "O uso de um objeto". Em C. Winnicott, R. Shepperd \& M. Davis (Orgs.), Explorações Psicanalíticas (pp. 170-177). Porto Alegre: Artes Médicas.

Enviado: 15.04 .2004

Revisado: 15.05 .2004 Aceito: 20.06.2004 
Sobre as autoras:

Sandra Augusta de Melo: Docente do Centro Universitário do Triângulo - Endereço eletrônico: sandra_augusta@terra.com.br Anália S. Costa: Estudante de Psicologia em iniciação científica.

Graciela Cardarelli: Estudante de Psicologia em iniciação científica

Lívia Santa Cecília Moraes: Estudante de Psicologia em iniciação científica 